\title{
OPERATIONAL METHOD FOR IDENTIFICATION OF SPECIFIC CUTTING FORCE DURING MILLING
}

\author{
M. Janota ${ }^{1 *}$, P. Kolár ${ }^{1}$, M. Sulitka ${ }^{1}$ \\ ${ }^{1}$ Czech Technical University in Prague, Research Center of Manufacturing Technology, Prague, Czech Republic \\ ${ }^{*}$ Corresponding author; e-mail: m.janota@rcmt.cvut.cz
}

\begin{abstract}
Specific cutting force is a key parameter that is important for estimating cutting forces that occur during machining. This information is important for various applications. The most important application is estimation of the stability limit valid for the specific configuration of the machine tool, tool and workpiece. There are a number of procedures used to predict the specific cutting force through various preliminary tests. This paper focuses on an operational method during milling that allows estimation of the specific cutting force using direct information from the machine tool control system. The specific cutting force is calculated as the ratio between the material removal rate and the power measured on the spindle. The method enables easy in-process identification of the specific cutting force that is valid for the specific workpiece material and the specific cutting edge geometry. The method is demonstrated on practical examples.
\end{abstract}

\section{Keywords:}

Specific cutting force; Mechanistic approach; Chatter; Frequency response function

\section{INTRODUCTION}

One of the obstacles to utilization of the installed power of a machine tool spindle is the regenerative vibration of the machine tool-tool-workpiece system, which is called chatter. Chatter is related to the cutting process and the interaction in the machine-tool-workpiece structure, as presented by Tlusty and Polacek [Tlusty 1957] and Tobias and Fishwick [Tobias 1958]. The regenerative vibrations depend on the chip thickness, the system's structural stiffness and the specific cutting force. This fact was taken into account in the first basic formula for milling applications, presented in [Tlusty 1957]:

$$
a_{\text {plim }}=\frac{-1}{2 \cdot Z^{*} \cdot K_{c} \cdot \min (\operatorname{Re}(F R F))}
$$

Chatter simulation methods were investigated in subsequent years. Recent overviews of the state of the art of chatter research and chatter suppression were presented in [Altintas 2004], [Brecher 2009] and [Munoa 2016]. The tangential specific cutting force remains the fundamental parameter for chatter prediction characterizing the cutting ability of the cutting tool with specific cutting edge geometry during machining of a specific workpiece material.

Cutting force simulation is a cornerstone of chatter prediction. In general, the two main approaches are FEMbased and mechanistic models. FE methods also have the potential to simulate other related effects, typically the cutting temperature and tool wear. However, these methods need correctly identified fundamental material parameters [Arrazola 2013]. These FEM simulations are also time-demanding and therefore are not typically used to estimate the cutting force coefficients for chatter prediction.
Mechanistic models enable quick cutting force computation. These models are based on Martellotti's idea [Martellotti 1941, Martellotti 1945] that the cutting force is proportional to the uncut chip thickness and the specific cutting force (also called the cutting force coefficient). The specific cutting force can be modelled using an exponential model proposed by [Kienzle 1952] (2) or a linear model including the ploughing effect proposed by [Armarego 1969] (3):

$$
\begin{aligned}
& F_{c}=k_{c} \cdot b \cdot h=k_{c 1.1} \cdot h^{-m_{c}} \cdot K \cdot b \cdot h \\
& F_{c}=k_{c c} \cdot b \cdot h+k_{c e} \cdot b
\end{aligned}
$$

[Sabberwal 1962] presented a method for identification of the tangential, radial and axial cutting force coefficients related to the axial depth of cut and feed per tooth. [Fu 1984] and [Spiewak 1995] presented mechanistic models for identification of the cutting force coefficients using sets of experimental data. [Budak 1996] introduced an orthogonal to oblique transformation method that enables reduction of the number of experiments for the cutting force coefficients. Today, the orthogonal cutting database is recommended for solid end mills, drills, tools with a smooth rake face and a cutting edge without chamfer. Orthogonal database data can be successfully used for tools with a complex contour, e.g. helical tapered end mills or tools with a serrated cutting edge. On the contrary, mechanistic models based on a set of experimental data are recommended for exchangeable tips with a complex cutting edge geometry involving chip breakers, a varying rake surface and edge chamfer [Altintas 2012].

Specific cutting forces can be experimentally measured using two approaches: 1) direct measurement of cutting 
forces using a stationary or rotary dynamometer and consequential computation using the uncut chip thickness and axial depth of cut; or 2) an indirect approach using spindle power monitoring during the machining operation and consequential computation using the tool diameter, uncut chip thickness and axial depth of cut.

When determining the tangential cutting force coefficient for milling using the direct measurement method, only one insert is clamped onto the tool to evaluate the cutting force. Jayram tried to overcome this shortcoming [Jayram 2001]. [Satyanarayana 2011] attempted to describe the relationship between the cutting force and plate geometry. The dependence of the tangential cutting force coefficient on cutting conditions was presented by [Velchev 2009] and [Karpuschewski 2018].

These experiments show that the cutting force coefficients depend on many different parameters related to the cutting process setting. The main advantage of indirect methods is very quick in-process identification of the cutting forces. [Qiu 2018] published a method using monitoring of the spindle and feed drive performance during machining and idle time for turning applications. A complex approach using monitoring of all drives during milling was presented by [Altintas 2017] for virtual monitoring of machining forces.

The last alternative for determining the cutting force coefficients are tool producer catalogue values (used most often in practice). These catalogues typically present coefficients for the Kienzle model; see e.g. [Mitsubishi 2019] or [Sandvik 2019].

This paper presents an operational method for identification of the tangential cutting force coefficient during milling for chatter prediction. The main motivation for developing this method for estimating the specific cutting force is potential future automated optimization of the cutting process without the need for any complex apparatus. The method is based on measurement of the spindle power during milling of a constant material volume with a constant feed rate. The anticipated main advantage is easy and quick prediction of the machining stability limit. The method is described in section 2. The experimental conditional and obtained data for two demonstration cases are presented in section 3 . These data are analyzed using the proposed method and the standard mechanistic approach and are compared with catalogue values in section 4 . An application for chatter limit prediction is also presented. Section 5 deals with the method uncertainties. The paper conclusion is presented in section 6 .

\section{DESCRIPTION OF PROPOSED METHOD}

The machining performance of a machine tool is characterized by the volume of removed material per time unit (Material Removal Rate - MRR):

$$
M R R=a_{e} \cdot a_{p} \cdot v_{f}\left[\frac{\mathrm{cm}^{3}}{\min }\right]
$$

The MRR can be limited by the dynamic compliance of the structure or the installed spindle power. The relative performance calculated as the ratio of removed material and installed spindle power MRR/P $\left[\frac{\mathrm{cm}^{3} / \mathrm{min}}{\mathrm{kW}}\right]$ characterizes the force interaction between the tool cutting edge and the workpiece material. The MRR/P ratio is a reciprocal value of the tangential cutting force coefficient, as the basic unit analysis shows:

$$
\left[\frac{M R R}{P}\right]=\left[\frac{1}{K_{C}}\right]
$$

$$
\left[\frac{\left(\frac{\left[m^{3}\right]}{[s]}\right)}{[W]}\right]=\left[\frac{\left(\frac{\left[m^{3}\right]}{[s]}\right)}{\left[\frac{N m}{s}\right]}\right]=\left[\frac{m^{2}}{N}\right]=\frac{1}{[P a]}
$$

$P$ is the spindle power consumed with the cutting process; $M R R$ is the metal removal rate during constant immersion milling (5). The spindle power $P$ is characterized as the product of the spindle rotational speed and its torque. The power $P$ is concurrently the product of the tangential cutting force and cutting speed. Thus, $K_{c}$ in $(6 a)$ is the tangential cutting force coefficient that could also be used for chatter prediction simulation (1).

The proposed method is based on identification of $K_{c}$ through direct measurement of the spindle power during constant immersion milling and subsequent calculation of the cutting force coefficient. The spindle power and the feed can be measured as the waveforms of time-controlled axes: Servo trace (Sinumerik), TNCscope (HEIDENHAIN) and Servo Guide (Fanuc) respectively. The power consumed with the cutting process would be calculated as the difference between the measured total spindle power $P_{t}$ and the spindle power during idle running $P_{0}$ :

$$
P=P_{t}-P_{0}
$$

The tangential cutting force coefficient can be calculated directly:

$$
K_{C}=\frac{P}{M R R}
$$

\section{REFERENCE IDENTIFICATION OF THE SPECIFIC CUTTING FORCE}

\subsection{Experiment setup}

Two experiments of C45 steel milling were conducted to verify the proposed method. Two different cutting tools on two different machine tools were used; see Tab. 1 and Tab. 2. There was only one insert clamped onto the tool body for the basic experiments to enable clear analysis of the dynamometer signal. Another setup with more mounted cutting inserts was tested later (see section 4.2). The workpiece material was placed on a three-axis KISTLER 9255B dynamometer and a KISTLER 5017B1500 amplifier in order to obtain the reference data. The amplified data was sampled and processed using a B\&K PULSE analyzer. The experimental setup is shown in Fig. 1.

The actual measurement procedure was as follows. First, the linearity of the FRF dynamometer was verified using a modal hammer; see Fig. 2. The tool body was equipped with one insert only. Thus, the maximum tooth pass frequency was about $25.3 \mathrm{~Hz}$. For each measurement case, three cutting force components were measured: $F_{X}, F_{Y}$ and $F Z$. Concurrently, the spindle power was measured in the machine tool control system directly. There was one run of the experiment for every combination $f_{Z}-v_{c}$. Five levels of the cutting speed $v_{C}$ were used for every feed per tooth value $f_{z}$. The experiment was not full factorial; see the detailed overview in Appendix 1 for more details. These measured force data were used for subsequent analysis of the cutting coefficients; see the next section. The data obtained from the dynamometer were used to calculate the reference value of the cutting force coefficients. 


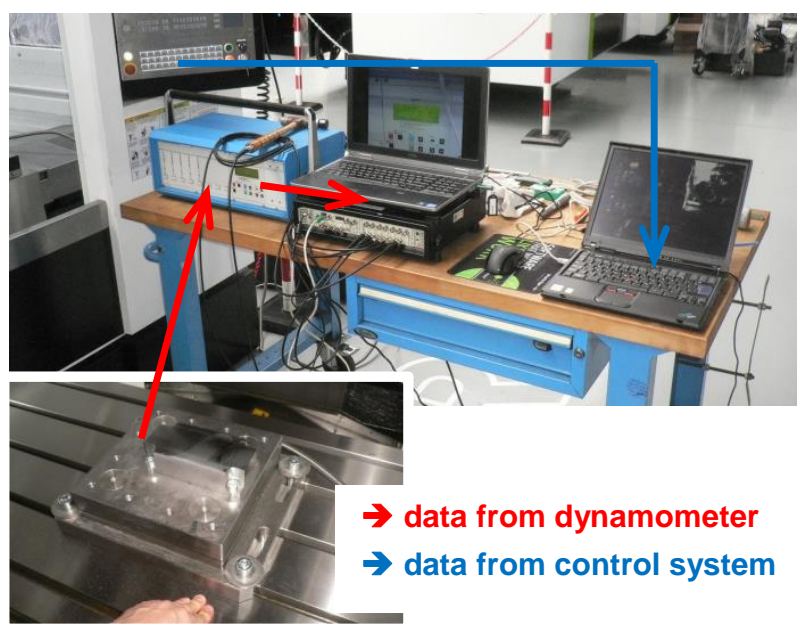

Fig. 1: Measurement apparatus.

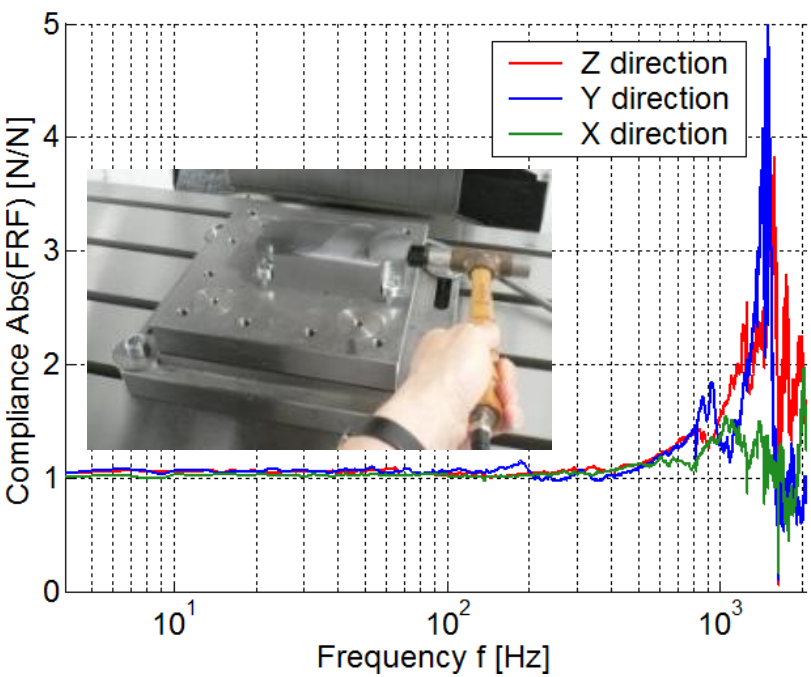

Fig. 2: Frequency response function of dynamometer.

Tab. 1: Case study 1: Tool and test conditions.
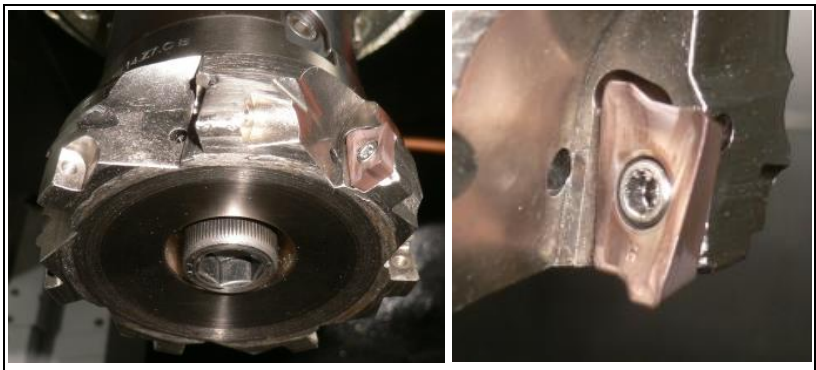

\begin{tabular}{|c|c|}
\hline $\begin{array}{l}\text { Machined } \\
\text { material: }\end{array}$ & C45 (170 HB) | 1.1191 (W.Nr.) \\
\hline Tool body: & $\begin{array}{l}\text { TGS F1600.100.N32.50.14.Z7.C } \\
\text { Dc }=100 \mathrm{~mm} \mid \mathrm{z}=7\end{array}$ \\
\hline Insert: & $\begin{array}{l}\text { SUMITOMO AXMT170508PEERH } \\
\text { ACP200 }\end{array}$ \\
\hline $\begin{array}{l}\text { Cutting } \\
\text { conditions: }\end{array}$ & $\begin{array}{l}v_{C}=100|150| 200|250| 300 \mathrm{~m} / \mathrm{min} \\
f_{Z}=0.10|0.15| 0.20|0.25| 0.30 \mathrm{~mm} \\
a_{e}=82 \mathrm{~mm} \\
a_{p}=1 \mathrm{~mm} \\
\text { Face milling }\end{array}$ \\
\hline Machine tool: & $\begin{array}{l}\text { Three-axis vertical machining centre } \\
\text { Belt driven spindle } 15 \mathrm{~kW} / 8000 \mathrm{rpm} \\
\text { HEIDENHAIN TNC } 620 \text { control system }\end{array}$ \\
\hline
\end{tabular}

Tab. 2: Case study 2: Tool and test conditions.
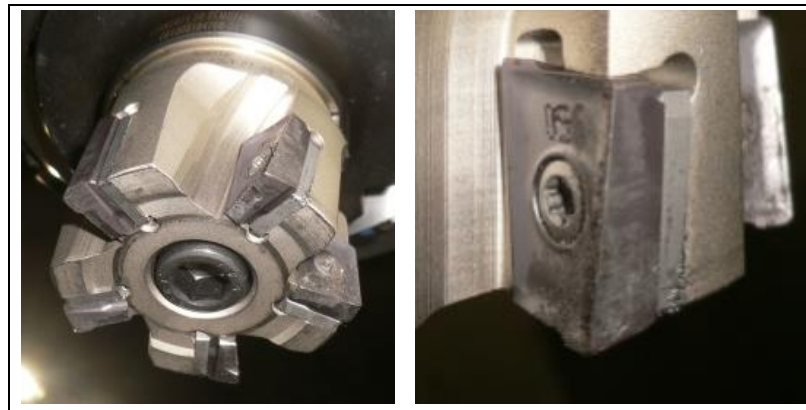

\begin{tabular}{|ll|}
\hline $\begin{array}{l}\text { Machined } \\
\text { material: }\end{array}$ & C45 (170 HB) | 1.1191 (W.Nr.) \\
\hline Tool body: & ISCAR 3M F90AX D063-27-20 \\
& DC $=63 \mathrm{~mm} \mid \mathrm{z}=5$ \\
\hline Insert: & ISCAR \\
& 3M AXKT 2006PDTR-RM \\
\hline Cutting & $v_{C}=100 / 150 / 200 / 250 / 300 \mathrm{~m} / \mathrm{min}$ \\
& $f_{z}=0.10 / 0.15 / 0.20 / 0.25 / 0.30 \mathrm{~mm}$ \\
& $a_{e}=63 \mathrm{~mm}$ \\
& $a_{p}=1 \mathrm{~mm}$ \\
& Slot milling \\
\hline Machine tool & Five-axis vertical machining centre \\
& with rotary-tilting table \\
& Belt driven spindle $40 \mathrm{~kW} / 10000 \mathrm{rpm}$ \\
& HEIDENHAIN TNC620 control system
\end{tabular}

\subsection{Specific cutting force calculation from the dynamometer data}

The procedure for processing the measured data was as follows. In the first step, three cutting force components were measured using the dynamometer for each cutting condition in the stationary coordinate system of the machine tool: Fx, Fy, and Fz. Then, a low-pass filter was applied to all components to remove unwanted high frequency components (Fig. 3). The active force $F_{A}$ was then calculated using Eq. 9:

$$
F_{a}=\sqrt{F_{x}^{2}+F_{y}^{2}}
$$

The maximum Fa was identified. For this situation, the chip thickness was considered in a simplified way as $h=f_{z}$. The parameter $\mathrm{K}_{\mathrm{c}}$ was then calculated using Eq. 10:

$$
K_{c}=\frac{\max \left(F_{a}\right)}{f_{z} \cdot a_{p}}
$$

Note that Eq. 10 is valid for clearly separated signals of every engaged tooth. In this case, a one-tooth tool was used, thus this basic condition was satisfied.

The resulting dependence of $K_{C}$ on the feed per tooth $f_{Z}$ is shown in Fig. 5. Kienzle model coefficients using leastsquare regression were computed to enable a comparison with typical catalogue values:

$$
K_{C}\left(f_{Z}\right)=k_{C 1.1} \cdot h^{-m_{C}}
$$

For this specific case, $h=f_{z}$. The results of the regression are shown in Tab. 4A. 


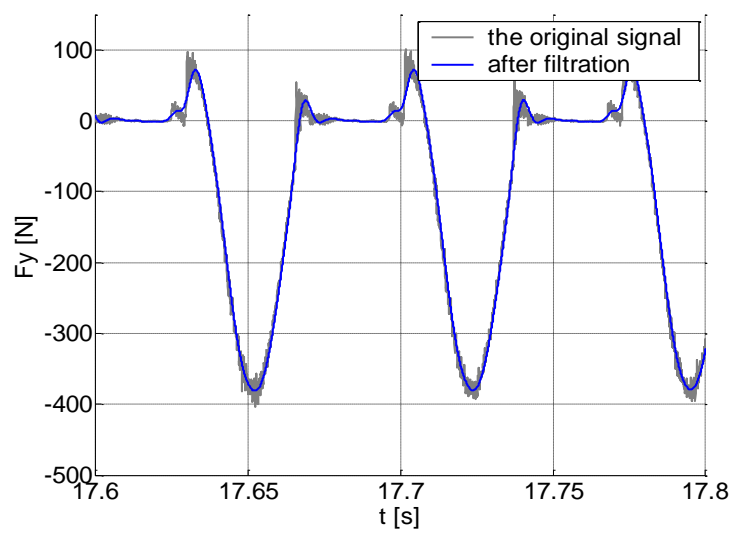

Fig. 3: Example of low-pass filtering of measured data.

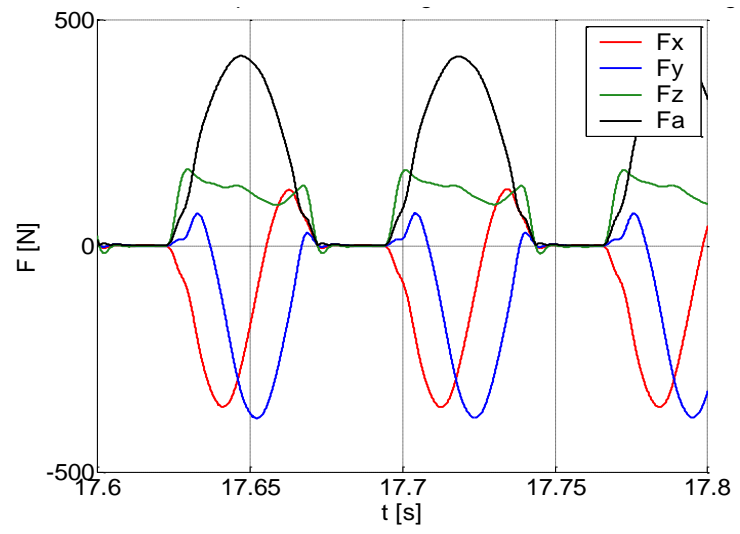

Fig. 4: Cutting forces $F_{X}, F_{Y}, F_{Z}$ measured with the dynamometer and calculated active force $F_{A}(9)$.

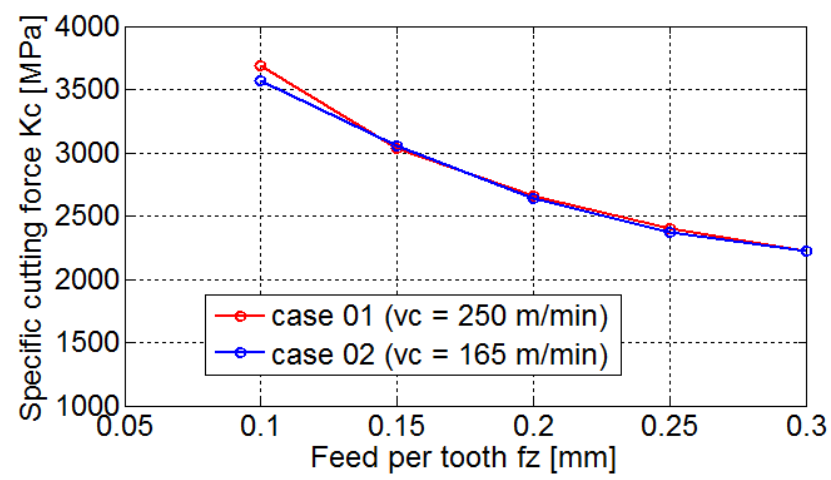

Fig. 5: Dependence of calculated specific cutting force $K_{c}$ on feed per tooth $f_{z}$ for both cases using the dynamometer data.

Looking at the dependence of the specific cutting force $K_{c}$ on the feed per tooth $f_{z}$, it is clear that $K_{c}$ decreases as $f_{z}$ increases. This fact is well known. It confirms that the data measured with the dynamometer are correct. These data are used in the next section as the reference data for validation of the P/MRR method results.

\section{IDENTIFICATION OF THE SPECIFIC CUTTING FORCE USING THE P/MRR METHOD}

\subsection{Procedure description}

The spindle power consumption was recorded using the machine tool control system during idle running and during machining (Fig. 6). The power consumed with the cutting process was calculated:

$$
P=\operatorname{mean}\left(P_{t}\right)-\operatorname{mean}\left(P_{o}\right)
$$

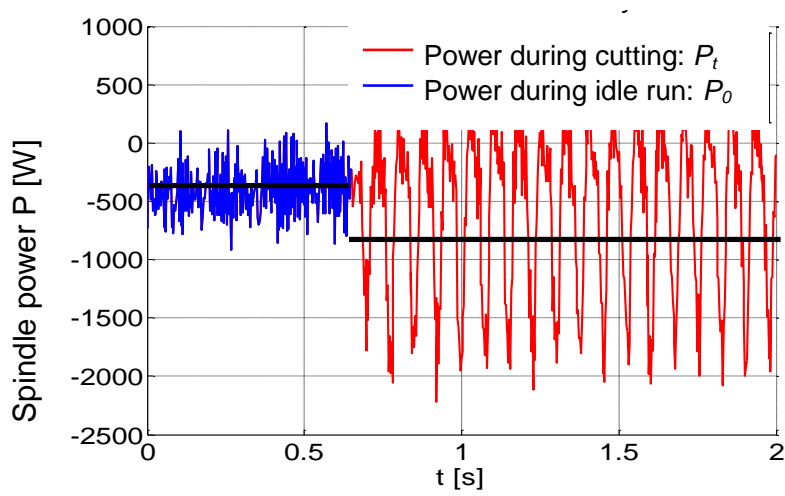

Fig. 6: Example of power signal measurement. The black lines indicate mean signal values.

The metal removal rate $M R R$ was calculated using known immersion values and the feed rate (5). The specific cutting force $K_{c}$ was calculated using Eq. 8. The results of machining with one installed insert were measured and evaluated for both tools. For case study 02 , machining with the full number of installed inserts was performed.

\subsection{Comparison of results}

The dependence of the calculated specific cutting force $K_{c}$ on the feed per tooth $f_{z}$ is presented in Fig. 7 and Fig. 9. The characteristic curve shape is visible again. The results from the dynamometer are used as a reference. The deviation of the P/MRR results is about $\pm 5 \%$ compared to the dynamometer results. The results calculated from the tool with one installed insert and five installed inserts are almost identical; see Fig. 9.

The data obtained from the Sandvik catalogue are presented as a typical example of the data available in the industry. For milling of C45 steel, the catalogue gives underestimated values for lower $f_{Z}$ values.

Kienzle model coefficients were identified for the P/MRR results and also for catalogue data using Eq. 11; see Tab. 4B and Tab. 4C.

The dependence of the calculated specific cutting force $K_{C}$ on the cutting speed $v_{c}$ is presented in Fig. 8 and Fig. 10. The $K_{c}$ value has low sensitivity to the vc as would be expected for the cutting speed range of $100-300 \mathrm{~m} / \mathrm{min}$.
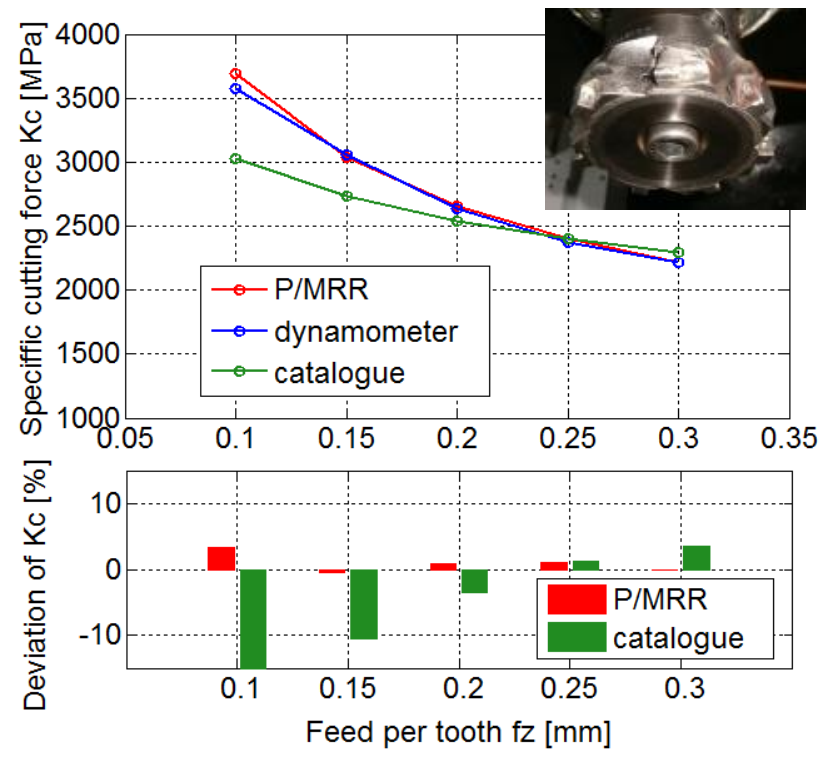

Fig. 7: Dependence of $K_{c}$ on $f_{z}$ for case study 01.

Example for $v_{C}=250 \mathrm{~m} / \mathrm{min}$. The dynamometer data is a reference for the deviation calculation. 


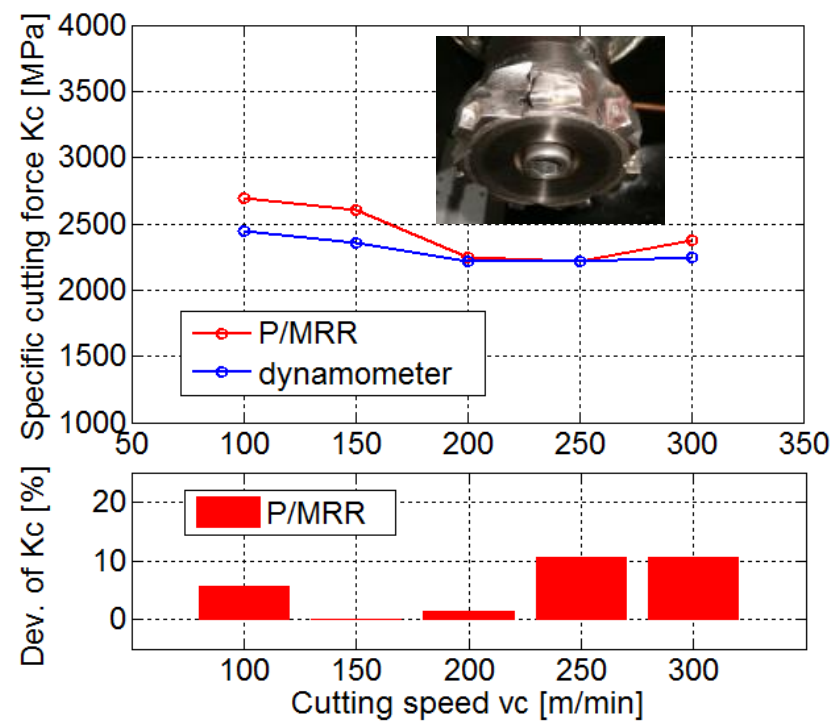

Fig. 8: Dependence of $K_{c}$ on $v_{c}$ for case study 01. Example for $f_{z}=0.30 \mathrm{~mm}$. The dynamometer data is a reference for the deviation calculation.
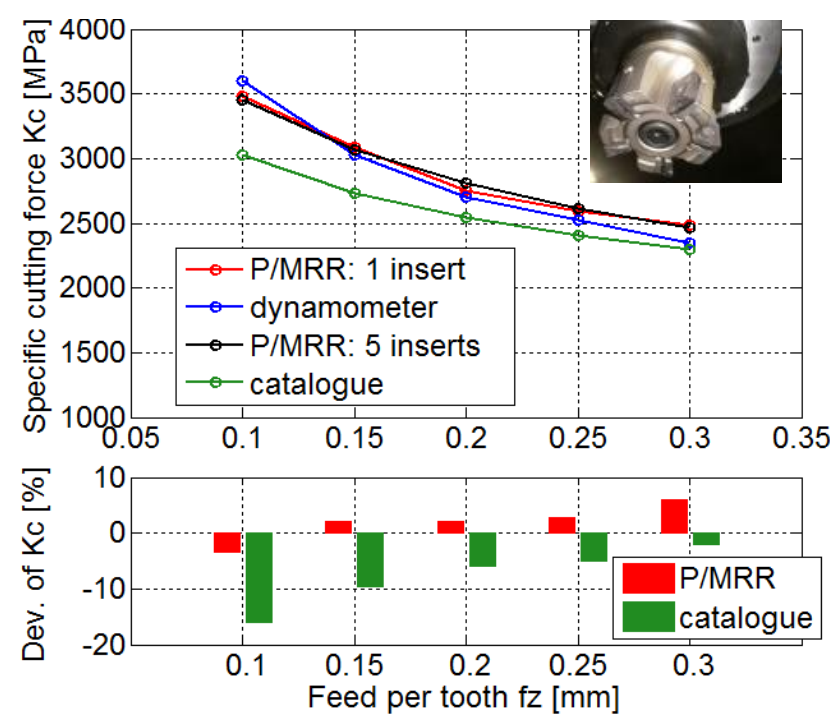

Fig. 9: Dependence of $K_{c}$ on $f_{z}$ for case study 02. Example for $v_{C}=165 \mathrm{~m} / \mathrm{min}$. The dynamometer data is a reference for the deviation calculation.

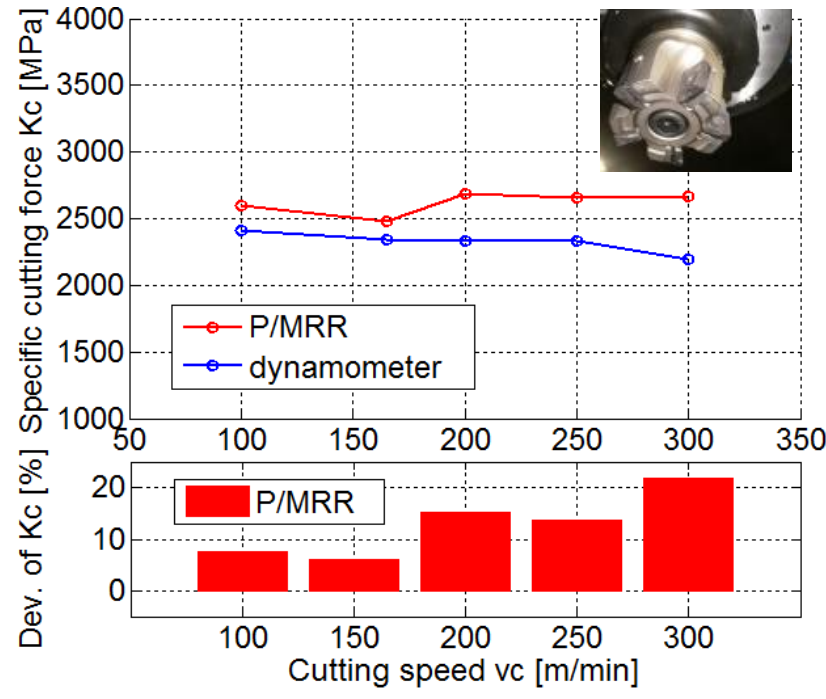

Fig. 10: Dependence of $K_{c}$ on $v_{c}$ for case study 02. Example for $f_{z}=0.30 \mathrm{~mm}$. The dynamometer data is a reference for the deviation calculation.
Tab. 4: Cutting force coefficients of the Kienzle model identified from various data sources.

\begin{tabular}{|c|c|c|}
\hline \multicolumn{3}{|c|}{ A) Data obtained from dynamometer measurement } \\
\hline Case no. & $\mathbf{k}_{\mathbf{c 1 . 1}}[\mathbf{M P a} / \mathbf{m m}]$ & $\mathbf{m}_{\mathbf{c}}[-]$ \\
\hline 01 & 1294 & 0.44 \\
\hline 02 & 1498 & 0.39 \\
\hline
\end{tabular}

B) Data calculated using the P/MRR method

\begin{tabular}{|c|c|c|}
\hline Case no. & $\mathbf{k}_{\mathbf{c 1 . 1}}[\mathbf{M P a} / \mathbf{m m}]$ & $\mathbf{m}_{\mathbf{c}}[\mathbf{-}]$ \\
\hline 01 & 1262 & 0.47 \\
\hline 02 (1 insert) & 1687 & 0.31 \\
\hline 02 (5 inserts) & 1713 & 0.31 \\
\hline
\end{tabular}

C) Data calculated from tool catalogue figures

\begin{tabular}{|c|c|c|}
\hline Catalogue & $\mathbf{k}_{\mathbf{c 1 . 1}}[\mathbf{M P a} / \mathbf{m m}]$ & $\mathbf{m}_{\mathbf{c}}[-]$ \\
\hline [Sandvik 2019] & 1700 & 0.25 \\
\hline
\end{tabular}

\subsection{Verification with stability lobe diagram}

An analysis of the stable machining conditions was conducted as an additional validation of the results. The specific cutting force $K_{c}$ estimated with the P/MRR method was used for frequency domain simulation (1) of the machining [SchmitzSmith 2009] using the F1600 tool (case $01, D=100 \mathrm{~mm}, Z=7$ ). As an input, the dynamic compliance was measured on the tool tip using a hammer tap test; see Fig. 11. The simulated stability limit was validated with cutting tests; see Fig. 12.
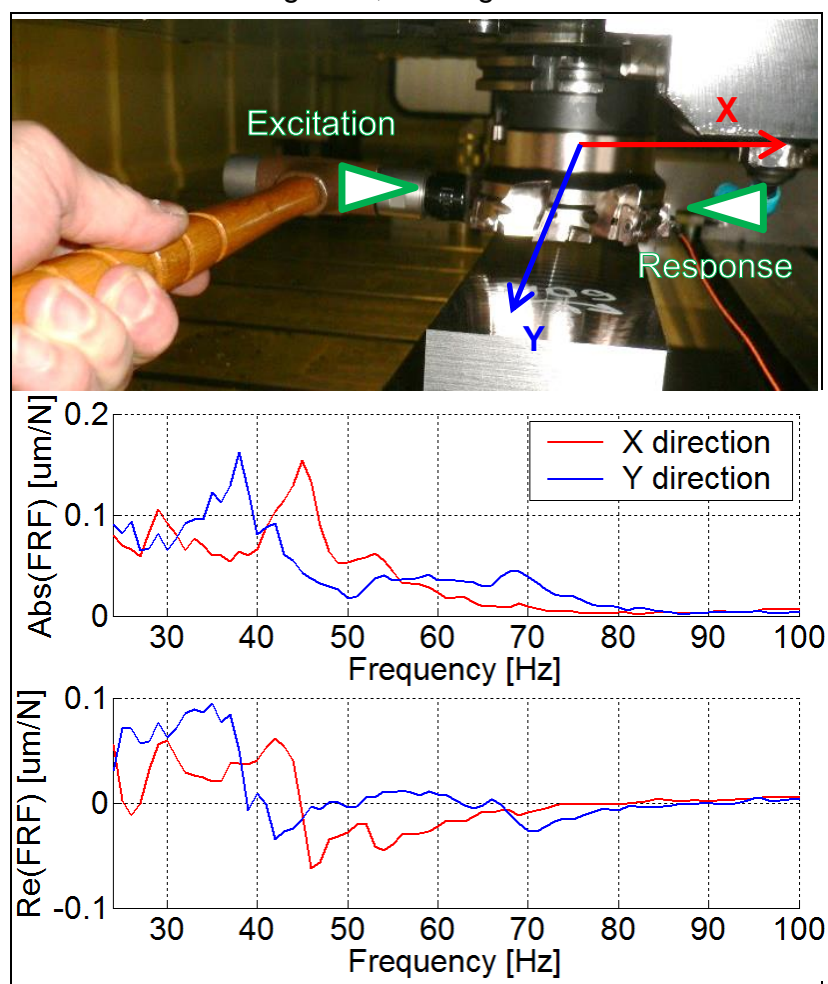

Fig. 11: Measurement of the dynamic compliance on the TGS F1600 cutting tool (above) and the measured frequency response function (below). The excitation and the response measurement were on the tool body. 

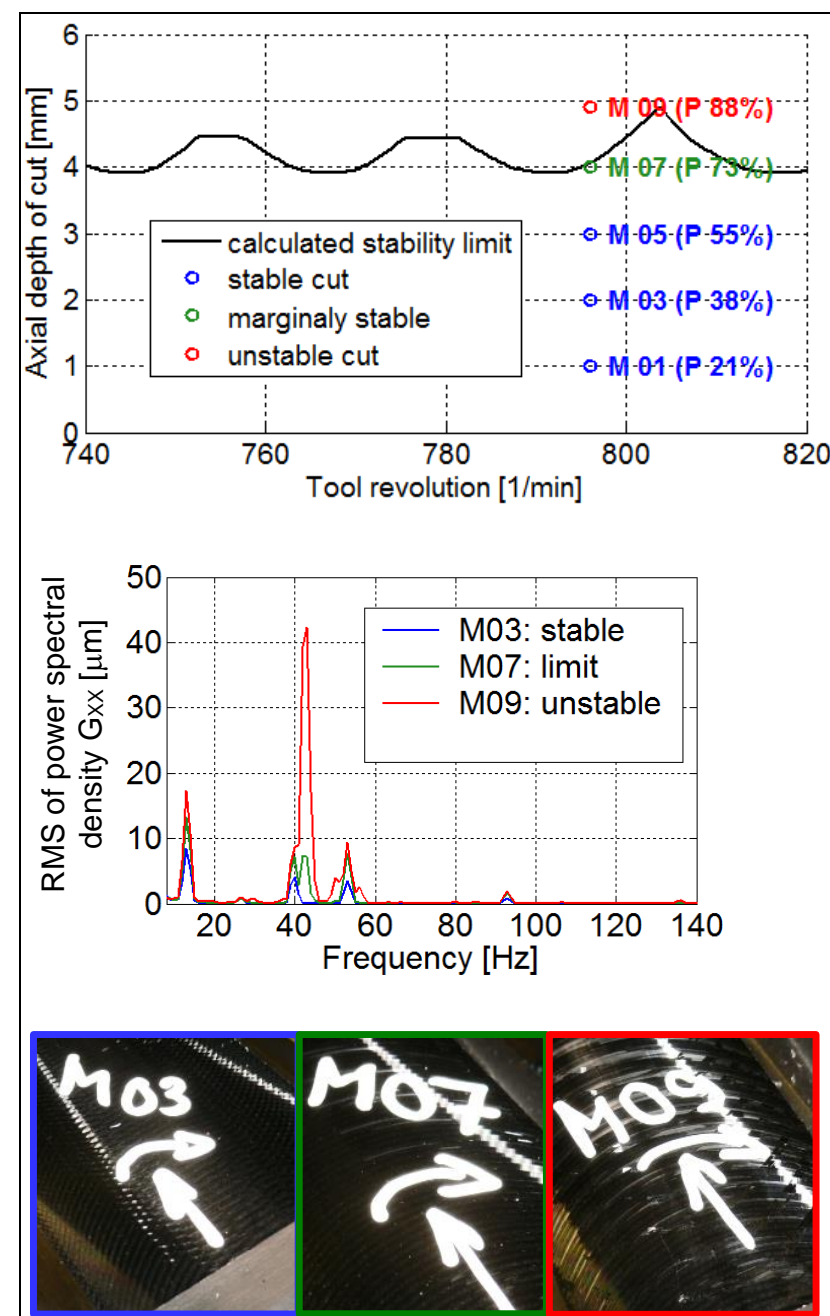

Fig. 12: Validation of calculated $K_{c}$ with the stability limit. The stability lobe diagram and trial cuts are shown on the top. The vibration spectra of selected cuts are shown in the middle. Photos of the machined surfaces are shown on the bottom.

\section{DISCUSSION}

An operational method for estimation of the tangential specific cutting force was presented. The main advantage of the method is that it is a quick and easy procedure that enables identification of the tangential specific cutting force as an important characterization of the specific cutting process.

The comparison of one-tooth-machining data showed that the P/MRR method yields results as a traditional approach using the dynamometer with an acceptable deviation within the range of $\pm 5 \%$. In general, the method uses the machining process total energy (12) and the total volume of the machined material. Thus, the number of currently engaged teeth is not important for the calculation as shown by the comparison of one-tooth-machining and five-teethmachining; see Fig 9. The cutting force coefficient calculated as the ratio of two total values also provides an opportunity to minimize the importance of other effects such as oscillation of the spindle power or local material inhomogeneity.

The presented machining experiments were performed with a low axial depth of cut of $1 \mathrm{~mm}$ to ensure a stable cut. In this case, the measurement results could be affected by the size of the cutting edge radius and the tool tip radius. It is probable that the real influence of these parameters is not very strong. The estimated specific cutting force was used for relevant prediction of the machining stability limit even on higher depths of cut (about $a_{p}=4 \mathrm{~mm}$ ). Nevertheless, further work is needed in this context to estimate the sensitivity of the method on tool engagement parameters.

Sumitomo and Iscar inserts were used. The results of calculated $K_{c}$ were compared with the Sandvik catalogue values, which has highly specified materials. The maximum difference of the catalogue values from the dynamometer results was $-15 \%$. The error is lower for higher feed per tooth values. Thus, the general data for C45 steel machining available in the catalogue are also useful.

The proposed method enables identification of the tangential specific cutting force $k_{c}$ during machining without the need to install any special force sensors. In industrial applications, continuous measurement would not be easy due to missing information about the real removed material volume per time (MRR). This information could be provided as a specific data file generated e.g. by simulation software that is able to simulate the removed material volume. As an alternative simplified method, the measurement could be done only at selected tool path sections where the removed material volume is well known.

\section{SUMMARY}

An operational method for specific cutting force estimation was presented. The method is based on calculation of the $\mathrm{P} / \mathrm{MRR}$ ratio. Two use cases executed on various two machine tools and two various tools show that the P/MRR method results have a low difference of $\pm 5 \%$ compared to the reference values measured with the dynamometer. In addition, the estimated specific cutting force value was successfully used to predict the machining stability limit. The entire procedure could be automated easily. One specialized cycle for making the identification cut can provide useful data for analysis of the cutting tool conditions.

\section{ACKNOWLEDGMENTS}

The authors would like to acknowledge funding support from the Czech Ministry of Education, Youth and Sports under the project CZ.02.1.01/0.0/0.0/16_026/0008404 "Machine Tools and Precision Engineering" financed by the OP RDE (ERDF). The project is also co-financed by the European Union. Support from the companies TGS and KOVOSVIT MAS Machine Tools for the experiments is also gratefully acknowledged.

\section{REFERENCES}

[Altintas 2004] Altintas, Y. and Weck, M. Chatter Stability of Metal Cutting and Grinding Virtual Machine Tool. CIRP Annals, 2004, Vol. 53, No. 2, pp. 619-642. https://doi.org/10.1016/S0007-8506(07)60032-8

[Altintas 2012] Altintas Yusuf. Manufacturing automation. 2nd ed. New York: Cambridge University Press, 2012. ISBN 978-1-107-00148-0

[Altintas 2017] Altintas, Y. and Aslan, D. Integration of virtual and on-line machining process control and monitoring. Annals of the CIRP. 2017, Vol. 66, No. 1, pp. 349-352. https://doi.org/10.1016/j.cirp.2017.04.047

[Arrazola 2013] Arrazola, P.J., Özel, T., Umbrello, D., Davies, M. and Jawahir, I.S. Recent advances in modelling of metal machining processes. CIRP Annals, 2013, Vol. 62, Issue 2, pp. 695-718. https://doi.org/10.1016/j.cirp.2013.05.006 
[Armarego 1969] Armarego, E.J.A. and Brown, R.H. The Machining of Metals. Prentice-Hall, 1969, 437 p.

[Brecher 2009] Brecher, C., Esser, M. and Witt, S. Interaction of manufacturing process and machine tool. CIRP Annals, 2009, Vol. 58, No. 2, pp. 588-607. https://doi.org/10.1016/j.cirp.2009.09.005

[Budak 1996] Budak, E., Altintas, Y. and Armarego, E. Prediction of milling force coefficients from orthogonal cutting data. Journal of Manufacturing Science and Engineering. 1996, Vol. 118, No. 2, 216-224.

[Fu 1984] Fu, H.J., Devor, R.E. and Kapoor, S.G. A mechanistic model for the prediction of the force system in face milling operations. Journal of Manufacturing Science and Engineering. 1984, Vol. 106, No. 1, 81-88.

[Jayram 2001] Jayram, S., S.G. Kapoor and R.E. Devor. Estimation of the specific cutting pressures for mechanistic cutting force models. International Journal of Machine Tools and Manufacture [online]. 2001, Vol. 41, No. 2, pp. 265-281. DOI: 10.1016/S0890-6955(00)00076-6. ISSN 08906955.

[Karpuschewski 2018] Karpuschewski, Bernhard, János Kundrák, Gyula Varga, István Deszpoth and Dmytro Borysenko. Determination of specific cutting force components and exponents when applying high feed rates. Procedia CIRP. 2018, Vol. 77, pp. 30-33. DOI: 10.1016/j.procir.2018.08.199. ISSN 22128271.

[Kienzle 1952] Kienzle, O. Die Bestimmung von Kraften und Leistungen an Spanenden Werkzeugen und Werkzeugmaschinen. VDI-Z, Vol. 94, No. 11, 1952, pp. 299-305.

[MITSUBISHI 2019] MITSUBISHI MATERIALS CORPORATION Formulae for Cutting Power. MITSUBISHI MATERIALS Web Catalog-Turning Tools, Rotating Tools, Tooling Solutions [online]. Available from: http://www.mitsubishicarbide.net/contents/mhg/enuk/html/ product/technical_information/information/formula4.html

[Martellotti 1941] Martellotti, M.E. An analysis of the milling process. Transactions of ASME. 1941, Vol. 63, 677.

[Martellotti 1945] Martellotti, M.E. An analysis of the milling process II. Down milling. Transactions of ASME. 1945, Vol. 67, 233.

[Munoa 2016] Munoa, J., Beudaert, X., Dombovari, Z. Altintas, Y., Budak, E., Brecher, C., Stepan, G. Chatter suppression techniques in metal cutting. CIRP Annals, 2016, Vol. 65, Issue 2, pp. 785-808. https://doi.org/10.1016/j.cirp.2016.06.004

[Qiu 2018] Qiu Jian. Modeling of cutting force coefficients in cylindrical turning process based on power measurement. The International Journal of Advanced Manufacturing Technology, September 2018, Vol.99, No. 9-12, pp 22832293. ISSN 0268-3768

[Sandvik 2019] Workpiece materials. Document Moved [online]. Copyright (C Sandvik Coromant [cit. 20.05.2019]. Available from: https://www.sandvik.coromant.com/en$\mathrm{gb} / \mathrm{knowledge/materials/pages/workpiece-materials.aspx}$

[Satyanarayana 2011] Satyanarayana, Kosaraju, Venugopal, A and Venkateswarao, G, 2011. Effect of rake angle and feed rate on cutting forces in an orthogonal turning process. Trends in Mechanical and Industrial Engineering (ICTMIE'2011). 2011.

[Sabberwal 1962] Sabberwal, A.J.P. Cutting forces in down milling. International Journal of Machine Tool Design and Research. 1962, Vol. 2, 27-41.

[SchmitzSmith 2009] Schmitz, T.L. and Smith, K.S. Machining Dynamics: Frequency Response to Improved Productivity. Springer 2009. ISBN 978-0-387-09644-5.

[Spiewak 1995] Spiewak, S. An improved model of the chip thickness in milling. Annals of the CIRP. 1995, Vol. 44, No. 1, 39-42.

[Tlusty 1957] Tlusty J. and Polacek, M. Beispiele der Behandlung der selbsterregten Schwingung der Werkzeugmaschinen. FoKoMa, Hanser Verlag, Munich 1957.

[Tobias 1958] Tobias, S.A. and Fishwick, W. Theory of regenerative machine tool chatter. The Engineer, Vol. 205, 1958.

[Velchev 2009] Velchev, S. Kolev, I. and Ivanov, K. Research on the Influence of the Cutting Speed on the Specific Cutting Force During Turning. Strojniški vestnik Journal of Mechanical Engineering. 2009. Vol. 55, No. 6, pp. 400-405.

\section{NOMENCLATURE:}

$F_{X}, F_{Y}, F_{Z} \quad[\mathrm{~N}] \quad$ cutting forces in the stationary coordinate system of the machine tool

$F_{A} \quad[\mathrm{~N}] \quad$ active cutting force

$F_{C} \quad[\mathrm{~N}] \quad$ tangential cutting force

Gxx [m] RMS value of power spectral density

$K \quad[-] \quad$ total correction factor

$K_{C} \quad[\mathrm{MPa}] \quad$ specific cutting force

$M M R\left[\mathrm{~cm}^{3} / \mathrm{min}\right]$ metal removal rate

$P \quad[\mathrm{~kW}] \quad$ power consumed by the cutting process

$P_{t} \quad[\mathrm{~kW}] \quad$ total spindle power measured during machining

$P_{0} \quad[\mathrm{~kW}] \quad$ spindle power during idle running

$Z \quad[-] \quad$ number of the tool teeth

$Z^{*} \quad[-] \quad$ teeth number engaged in the workpiece

$a_{e} \quad[\mathrm{~mm}]$ radial depth of cut

$a_{p} \quad[\mathrm{~mm}]$ axial depth of cut

$f_{z} \quad[\mathrm{~mm}]$ feed per tooth

$f_{V} \quad[\mathrm{~mm} / \mathrm{min}]$ feed rate

$k c 11$ [MPa] specific cutting force, $a_{p}=h=1 \mathrm{~mm}$

$h \quad[\mathrm{~mm}]$ average chip thickness

$m_{c} \quad[-] \quad$ exponent of the specific cutting force

$v_{C} \quad[\mathrm{~m} / \mathrm{min}] \quad$ cutting speed 


\section{APPENDIX 1: OVERVIEW OF THE MEASURED FIGURES}

Table 5: Experiment data for case study 01, machining with one tooth.

\begin{tabular}{|c|c|c|c|c|c|c|c|c|c|}
\hline ID & $a_{p}[\mathrm{~mm}]$ & $a_{e}[\mathrm{~mm}]$ & $\begin{array}{c}V_{c} \\
{[\mathrm{~m} / \mathrm{min}]}\end{array}$ & $f_{z}[\mathrm{~mm}]$ & $\mathbf{Z}[-]$ & $\begin{array}{c}\text { MRR } \\
{\left[\mathrm{cm}^{3} / \mathbf{m i n}\right]}\end{array}$ & $P_{o}[k W]$ & $P_{t}[\mathrm{~kW}]$ & $K_{c}[\mathrm{MPa}]^{*}$ \\
\hline 1 & 1 & 82 & 250 & 0.10 & 1 & 6.5 & 0.27 & 0.68 & 3689.9 \\
\hline 2 & 1 & 82 & 250 & 0.15 & 1 & 9.8 & 0.27 & 0.77 & 3038.5 \\
\hline 3 & 1 & 82 & 250 & 0.20 & 1 & 13.1 & 0.27 & 0.85 & 2657.0 \\
\hline 4 & 1 & 82 & 250 & 0.25 & 1 & 16.3 & 0.27 & 0.93 & 2398.5 \\
\hline 5 & 1 & 82 & 250 & 0.30 & 1 & 19.6 & 0.27 & 1.00 & 2217.9 \\
\hline 6 & 1 & 82 & 200 & 0.30 & 1 & 15.7 & 0.25 & 0.84 & 2251.6 \\
\hline 7 & 1 & 82 & 150 & 0.30 & 1 & 11.7 & 0.34 & 0.85 & 2603.1 \\
\hline 8 & 1 & 82 & 100 & 0.30 & 1 & 7.8 & 0.19 & 0.54 & 2696.6 \\
\hline 9 & 1 & 82 & 300 & 0.30 & 1 & 23.5 & 0.32 & 1.25 & 2376.3 \\
\hline
\end{tabular}

Table 6: Experiment data for case study 02, machining with 1 tooth and 5 teeth.

\begin{tabular}{|c|c|c|c|c|c|c|c|c|c|}
\hline ID & $a_{p}[\mathrm{~mm}]$ & $a_{e}[\mathrm{~mm}]$ & $\begin{array}{c}v c \\
{[\mathrm{~m} / \mathrm{min}]}\end{array}$ & $f_{z}[\mathrm{~mm}]$ & $\mathbf{Z}[-]$ & $\begin{array}{c}\text { MRR } \\
{\left[\mathrm{cm}^{3} / \mathbf{m i n}\right]}\end{array}$ & $P_{o}[k W]$ & $P_{t}[\mathrm{~kW}]$ & $K_{c}[\mathrm{MPa}]^{\star}$ \\
\hline 10 & 1 & 63 & 165 & 0.10 & 1 & 5.3 & 0.14 & 0.44 & 3477.6 \\
\hline 11 & 1 & 63 & 165 & 0.15 & 1 & 7.9 & 0.14 & 0.54 & 3084.9 \\
\hline 12 & 1 & 63 & 165 & 0.20 & 1 & 10.5 & 0.14 & 0.62 & 2753.4 \\
\hline 13 & 1 & 63 & 165 & 0.25 & 1 & 13.1 & 0.14 & 0.71 & 2596.7 \\
\hline 14 & 1 & 63 & 165 & 0.30 & 1 & 15.8 & 0.14 & 0.79 & 2485.0 \\
\hline 15 & 1 & 63 & 165 & 0.10 & 1 & 5.3 & 0.14 & 0.48 & 3936.5 \\
\hline 16 & 1 & 63 & 100 & 0.30 & 1 & 9.5 & 0.09 & 0.50 & 2597.4 \\
\hline 17 & 1 & 63 & 200 & 0.30 & 1 & 19.1 & 0.14 & 0.99 & 2684.8 \\
\hline 18 & 1 & 63 & 250 & 0.30 & 1 & 23.9 & 0.10 & 1.15 & 2655.0 \\
\hline 19 & 1 & 63 & 300 & 0.30 & 1 & 28.6 & 0.18 & 1.45 & 2671.8 \\
\hline 20 & 1 & 63 & 165 & 0.20 & 1 & 10.5 & 0.14 & 0.66 & 2958.8 \\
\hline 21 & 1 & 63 & 165 & 0.25 & 1 & 13.1 & 0.14 & 0.73 & 2686.7 \\
\hline 22 & 1 & 63 & 165 & 0.10 & 5 & 26.3 & 0.14 & 1.65 & 3451.8 \\
\hline 23 & 1 & 63 & 165 & 0.15 & 5 & 39.4 & 0.14 & 2.15 & 3068.2 \\
\hline 24 & 1 & 63 & 165 & 0.20 & 5 & 52.5 & 0.14 & 2.60 & 2815.7 \\
\hline 25 & 1 & 63 & 165 & 0.25 & 5 & 65.7 & 0.14 & 3.00 & 2609.9 \\
\hline 26 & 1 & 63 & 165 & 0.30 & 5 & 78.8 & 0.14 & 3.38 & 2469.8 \\
\hline 27 & 1 & 63 & 165 & 0.20 & 5 & 52.5 & 0.14 & 2.60 & 2806.9 \\
\hline
\end{tabular}

${ }^{*} K_{C}$ calculated using the P/MRR method 